\title{
A REINVENÇÃO DA FORÇA DE TRABALHO EM TEMPOS DE CRISE: AUTONOMIA E PRECARIEDADE
}

\author{
Rejane Gomes Carvalho ${ }^{1}$
}

RESUMO: Neste artigo discute-se o processo de flexibilização do trabalho e as novas formas de submissão e exploração que reproduzem trabalhadores livres, precários e passivos. O avanço da tecnologia e do sistema de informação vem reforçar a individualização e racionalização do trabalho humano, recriando e ressignificando o lugar do trabalho na vida social. $\mathrm{O}$ aumento das ocupações por conta própria, a informalidade do trabalho e 0 crescimento dos microempreendedores individuais, expressam as condições estruturais de um ambiente econômico em transformação que tende a desenvolver atividades com características de trabalho precário, gerando baixas remunerações e ausência de direitos pelo trabalho, fatores que contribuem para a preservação e reprodução da pobreza e das desigualdades.

Palavras-chave: Trabalho; Flexibilização; Precarização; Direitos.

\section{THE REINVENTION OF THE WORKFORCE IN TIMES OF CRISIS: AUTONOMY AND PRECARIOUSNESS}

ABSTRACT: This article discusses the process of labour flexibility and the new forms of submission and exploitation that reproduce free, precarious and passive workers. The advance of technology and the information system reinforces the individualization and rationalization of human work, recreating and resignifying the place of work in social life. The increase in self-employment, the informality of work and the growth of individual micro-entrepreneurs express the structural conditions of an economic environment in transformation that tends to develop activities with characteristics of precarious work, generating low pay and no rights for work, factors that contribute to the preservation and reproduction of poverty and inequality.

Keywords: Work; Flexibility; Precarization; Rights.

\section{INTRODUÇÃO}

O processo de desconstrução de valores e direitos no âmbito das relações sociais de trabalho, observado em sua fase mais recente, a partir dos anos de 1990, em função da flexibilização do trabalho, tem contribuído para a aceitação da

\footnotetext{
${ }^{1}$ Economista, Mestre em Economia Rural, Doutora em Sociologia do Trabalho (UFPB). É professora da Universidade Federal da Paraíba. E-mail: rejanegcarvalho@yahoo.com.br.
} 
precariedade do trabalho como algo naturalizado na sociedade. Como parte do movimento de reorganização das forças produtivas, admite-se a acomodação da força de trabalho às necessidades de reprodução do sistema capitalista, o que se expressa com mais evidência pelas transformações tecnológicas que alteram a proporção dos investimentos entre capital e trabalho. Contudo, juntamente com as mudanças técnicas, faz-se necessário a legitimação política e social para que a reprodução do capital encontre as condições de sua permanência. Neste sentido, busca-se problematizar as novas formas de submissão e exploração da força de trabalho, manifestadas não somente no campo das relações materiais e formais da produção, mas como fortalecimento da dominação na dimensão dos valores e ideias, produzindo trabalhadores livres, precários e passivos.

Em um insistente cenário de crise econômica, fortalece-se a noção de que a retomada do crescimento da economia depende da diminuição dos custos trabalhistas, atribuindo-se a responsabilidade do progresso social à capacidade de flexibilização da força de trabalho. Com isso, a sociedade aceita passivamente a perda de direitos sociais do trabalho como se fosse essa a solução para aumentar os empregos e garantir o lugar do trabalhador no mercado. Além disso, cunhou-se um enredo fantasioso sobre a capacidade de gestão individual da força de trabalho e o empreendedorismo como exercício da autonomia dos trabalhadores em um mundo propício às desinserções e ao trabalho instável. É assim que se naturaliza a condição de informalidade e precariedade do trabalho e se justifica a destruição de direitos, tornando os trabalhadores mais vulneráveis na perpetuação da pobreza.

Embora se reconheça o forte apelo ideológico que visa diminuir a centralidade e a importância do trabalho humano na sociedade capitalista, a submissão formal e real do trabalho ao capital expressa a relação de forças que viabiliza a continuidade do modelo de reprodução do capital, mas recria outras formas de sujeição que se manifestam na relação social do trabalho a partir de novas modalidades de contratação da força de trabalho, explicitando a redução de direitos em um contexto de desregulamentação e flexibilização das relações de trabalho. Nessa disputa desigual por lugares sociais, não é possível garantir que as concessões dos trabalhadores promovam mais crescimento econômico e empregos, tendo em vista que as mudanças estruturais entre capital e trabalho representam a renovação das 
condições de reprodução do lucro e não a criação de novas ocupações para os trabalhadores.

As mudanças estruturais na reorganização da acumulação capitalista apontam para a redução relativa do emprego formal e o aumento de ocupações por conta própria e atividades informais, estimulando o empreendedorismo precário e a autogestão da exclusão por parte da força de trabalho. Testemunha-se o surgimento de um novo modelo na relação social entre capital e trabalho, onde o Estado se mostra parceiro do capital, criando as condições institucionais e jurídicas para a expansão do sistema, o que pode ser visto nas reformas implementadas na legislação trabalhista nos anos de 1990 em diante.

Além dessa introdução, o artigo está organizado em três partes. Na primeira, apresenta-se uma discussão sobre a importância do trabalho humano no sistema capitalista e a definição do lugar do trabalhador na sua relação com o capital, tendo em vista o processo contínuo de desqualificação do trabalho como fator essencial na criação de riqueza. Na segunda parte, destaca-se a condição de submissão do trabalhador no processo produtivo e as novas formas de controle a que estes trabalhadores estão expostos frente ao avanço das tecnologias. Ao mesmo tempo observa-se o surgimento de padrões comportamentais construídos ideologicamente a partir da ideia de liberdade, autonomia e capacidade empreendedora, a estimular a conduta individualista na busca pela inserção profissional e promover a desmobilização das demandas coletivas pelos direitos trabalhistas. Na terceira parte, analisa-se as condições do mercado de trabalho no Brasil a partir das ocupações formais, informais e rendimentos, buscando entender as mudanças ocupacionais, tendo em vista o grande número de pessoas que sobrevivem nas atividades informais, por conta própria e como microempreendedores individuais. Nas considerações finais, reflete-se sobre a possível ampliação da informalidade e precariedade do trabalho no Brasil, considerando que as mudanças recentes podem aumentar a instabilidade no trabalho e as desinserções.

\section{O LUGAR DO TRABALHO HUMANO NA RELAÇÃO COM O CAPITAL}

$O$ debate estabelecido em torno do trabalho humano enquanto elemento central, ou não, para a determinação da riqueza, e o papel dos sujeitos na sociedade, pode parecer um tema superado em função da mistificação promovida sobre a ideia de uma vida orientada pela liberdade de gerenciar o próprio trabalho e 
o tempo livre. Mas, em contraposição a esta noção de liberdade, a realidade anuncia uma sociedade monitorada pelo avanço da técnica e do sistema de informação como sinal de individualização e racionalização da conduta humana, recriando e ressignificando o lugar do trabalho na vida social, assim como o papel dos sujeitos.

De acordo com Mészáros a estrutura do sistema capitalista reduziu:

(...) os seres humanos à condição reificada (por meio da qual eles são trazidos a um denominador comum com as "locomotivas" e outras máquinas e tornam-se substituíveis por elas) e à posição ignominiosa de carcaça do tempo (MÉSZÁROS, 2007, p. 43).

A importância desse processo está exatamente na desconstrução do lugar social do trabalho que ocorreu em função da expropriação do saber do trabalhador, o que significa a perda de controle do trabalho de concepção na produção. O trabalhador foi amplamente expropriado no processo de trabalho quando as máquinas invadiram a produção tomando o seu lugar, separando o trabalho intelectual do manual e submetendo-o a um novo ritmo no processo de trabalho. Desse modo, "o instrumental de trabalho liquida, então, o trabalhador" (MARX, 1989, p. 494), destruindo o lugar dos trabalhadores de ofício, o saber e a liberdade dos sujeitos, exigindo a contínua adaptação ao sistema das fábricas e a incessante qualificação profissional, num movimento contínuo de alienação e aperfeiçoamento do controle do capital sobre o trabalho.

A produção capitalista, considerando o grau de desenvolvimento técnico, vai se orientar sempre de modo a aperfeiçoar o controle do capital sobre o processo de trabalho, renovando as formas de apropriação dos valores gerados pelos trabalhadores, bem como as relações de poder que se vão estabelecendo para a legitimação do sistema. Nesse movimento, o embate entre exploradores e explorados cria um cenário permanente de luta para existir: o capitalista buscando a permanência e manutenção do seu controle, e os trabalhadores reprimidos, requerendo espaços perdidos e sentidos de vida.

Assim, essa forçada habituação do trabalhador às necessidades da produção capitalista significa destruição de vidas humanas não somente no sentido da subsistência, mas também das relações sociais e políticas, das identidades, dos valores e da moral de sujeitos que têm sua existência construída em função de uma vida no trabalho. Todo esse movimento que conduz à transformação da base técnica 
na produção e à mudança de lugar do sujeito, representa a tentativa de objetivar o trabalho humano no processo de trabalho, diminuindo a sua importância na geração de riqueza, assim como a visibilidade do sujeito na sociedade. O contraditório é verificado na inversão de posição entre trabalhador e capitalista, quando a este último é atribuído o mérito de sujeito empreendedor, gerador de empregos, benfeitor e o mais importante colaborador para o progresso da nação. Quanto mais a divisão do trabalho é ampliada e mais tecnificadas se tornam as funções na produção das mercadorias, mais o trabalho humano é associado a uma ferramenta apenas necessária ao livre funcionamento das máquinas. Desse modo, o trabalhador aparece com menos conteúdo político e associado ao atraso e à falta de iniciativa.

O grande desafio da sociedade presente é alcançar uma formação para o trabalho que esteja diretamente conectada com a edificação da vida social, em que se conceba um sujeito pleno em suas habilidades técnicas, útil para o trabalho, mas que também possa exercer o direito à cidadania, capaz de pensar criticamente e posicionar-se politicamente. A esta perspectiva inclusiva contrapõe-se o desenvolvimento do trabalho autônomo, resignado e instrumentalizado. O controle técnico sobre o processo de trabalho significou a perda de autoridade do trabalhador sobre os elementos materiais da produção, mas também a falta de domínio desse trabalhador sobre sua própria vida. O controle técnico do capital sobre a produção significa, portanto, o comando da formação do sujeito no sentido de pensar, agir e existir. Assim, na medida em que o sistema do capital cria a necessidade inesgotável de qualificação profissional para os trabalhadores, considerando-os sempre desqualificados diante do frenético avanço tecnológico, na verdade está promovendo o adestramento em massa da força de trabalho, tornando-os civilizados e educados para o trabalho, uma vez que, instruídos, tornam-se competentes e úteis para a sociedade. Portanto, o imperativo da formação profissional, das competências e da flexibilidade do trabalhador, mais do que uma carência técnica, contempla a intenção de tornar útil a força de trabalho para ser explorada.

É da essência do sistema capitalista buscar a acumulação de riqueza por meio do controle e da exploração do trabalho alheio e pela reificação do processo produtivo, fazendo com que toda a força produtiva do trabalho pareça capacidade criadora do capital, sacrificando não somente a posição do trabalhador na relação material da produção, mas corrompendo a individualidade, o saber profissional e a capacidade de pensar e agir como sujeito social. A respeito do processo de 
reificação do trabalhador no sistema de produção, a reflexão de Arendt continua bastante reveladora:

(...) a liberação da força de trabalho como processo natural não se restringiu a certas classes da sociedade, e a apropriação não terminou com a satisfação das necessidades e desejos; o acúmulo de capital, portanto, não levou à estagnação que se vê tão claramente em ricos impérios que precederam a era moderna, mas infiltrou-se por toda a sociedade e deu início a um fluxo constantemente crescente de riqueza. (....) O processo de acúmulo de riqueza, tal como o conhecemos, estimulado pelo processo vital e, por sua vez, estimulando a vida humana, é possível somente se o mundo e a própria mundanidade do homem forem sacrificados (ARENDT, 2009, p. 267-8).

A produção da riqueza no capitalismo permite o exercício da relação de poder do capital sobre o trabalho, aprofundando-se e renovando-se na medida em que se desenvolvem e intensificam as inovações tecnológicas. Longe de parecer isento no movimento da criação de valores, o progresso técnico está carregado de conteúdo ideológico ao alimentar e fortalecer, no processo de trabalho, uma conduta voltada para o aperfeiçoamento das habilidades, das competências, da divisão do trabalho e do aumento de produtividade, o que implica em maior racionalidade no uso dos fatores produtivos, especialmente, da força de trabalho. Com a modernização da técnica na produção das mercadorias, o trabalho humano teve seu lugar tomado pelo capital morto e este passou a ser sinônimo de eficiência e produtividade. $O$ capital constante foi ocupando, progressivamente, a maior parte do capital investido em relação ao capital variável ${ }^{2}$, provocando o aumento do número de trabalhadores desocupados ou marginalizados (MARX, 1989).

Para os capitalistas, o progresso tecnológico é uma necessidade vital para a existência e reprodução do capital, uma vez que expressa a busca pelo aumento da produtividade do trabalho e a diminuição de custos frente à concorrência intercapitalista. No tocante aos trabalhadores, o avanço técnico não veio significar menos esforço no processo de trabalho e, menos ainda, alterar a relação de dominação na produção social de valores. A busca por maior lucro pelos capitalistas funciona como um estímulo permanente para aumentar o grau de exploração da força de trabalho, disfarçada na concessão de prêmios, como estímulo ao aumento da produtividade, no trabalho em domicílio, na flexibilização das tarefas, entre outras (MARX, 1989).

\footnotetext{
${ }^{2}$ Movimento denominado por Marx de lei geral da acumulação capitalista.
} 
Na essência, a liberdade do mercado é mistificadora e denota uma relação de submissão real do trabalho ao capital, como uma maquiagem produzida para disfarçar as condições de exploração e dominação nas quais se arquiteta o sistema capitalista outras (MARX, 1989). O movimento que garante a manutenção dessa base produtiva e a sua reprodução é dependente da contínua recriação das formas de controle e exploração do trabalho. Este movimento, ao mesmo tempo em que representa as forças que promovem a existência do capitalismo com base na submissão do trabalho, também pode ser o causador das crises, na medida em que estimula a centralização do capital, a queda da taxa geral de lucro, a crescente pauperização da classe trabalhadora e, consequentemente, a diminuição do potencial consumidor, indispensável à realização dos valores das mercadorias e do lucro. O trabalho humano é considerado indispensável à reprodução do capital e continua sendo central para a renovação das relações de poder, ainda que pareça estar desvanecendo-se em relação ao capital morto no processo produtivo. Mesmo que por meio de artifícios e com formas de trabalho que criam a ilusão do trabalho livre, a submissão do trabalho ao capital mostra-se cada vez mais viva na sociedade contemporânea.

O processo de acumulação no sistema capitalista, em sua forma produtiva só pode ocorrer a partir da relação técnica entre capital e trabalho, sendo renovado com o progresso tecnológico. Se o lucro resulta dos valores excedentes produzidos e da produção em escala ampliada, os capitalistas tendem a elevar a composição orgânica de capital, de modo a refletir a manutenção de sua existência diante de uma concorrência cada vez mais acirrada. Como a estrutura técnica do capital não permite alterar os investimentos em capital constante fixo no curto prazo, tendo em vista que as máquinas e equipamentos têm tempo de vida útil mais longo, além de serem resultado de dívidas firmadas junto ao capital financeiro, resta reduzir custos junto ao capital variável.

A força de trabalho, como componente flexível do capital, é impelida a adaptar-se aos novos procedimentos técnicos no processo de trabalho. Com a velocidade das mudanças tecnológicas associadas aos processos produtivos, especialmente considerando as condições trazidas pela indústria 4.0 no capitalismo do século $X X I$, o trabalhador passa a ocupar uma condição de desqualificação diante das exigências impostas para o aumento da produtividade. A requalificação das funções e procedimentos torna-se uma necessidade permanente do trabalhador 
integrado aos modelos de produção que incorporam as novas tecnologias da informação à gerência científica da produção, o que tende a se expandir para outros setores, mesmo que em intensidade diferenciada, como já vem ocorrendo nas atividades de comércio e serviços.

Para cumprir essa tendência de elevação da composição orgânica entre capital constante e capital variável, os elevados investimentos exigidos pelo progresso tecnológico alteram não somente a relação técnica, mas a relação social entre capital e trabalho. Constrói-se a mística de que o trabalho humano é desnecessário à reprodução do capital, tornando-se um custo cada vez mais pesado, o que também caracteriza uma construção social para desqualificar a importância do trabalho humano enquanto criador de riqueza.

\section{SUBMISSÃO E FLEXIBILIZAÇÃO DA FORÇA DE TRABALHO}

A lógica imediata do capital está pautada na redução de custos para que as condições da sua reprodução continuem a existir. Desse modo, a crise estrutural do capital, delineada em sua fase mais recente a partir dos primeiros anos do século $\mathrm{XXI}$, significa, mais uma vez, a reorganização da relação técnica entre capital e trabalho, concomitante aos rearranjos institucionais, políticos e jurídicos da relação social e formal estabelecida entre eles. Na essência, a flexibilização da força de trabalho é a reafirmação da submissão do trabalho ao capital, expressando uma capacidade de dominação que reverbera sobre diferentes dimensões na vida do trabalhador, quer seja na organização política, na cultura, nas ideias e nas condições sociais em que vive.

O domínio do processo de trabalho passa a ser determinado pelo ritmo das máquinas, monitoradas por softwares e sistemas de informação sofisticados, fazendo com que o trabalho humano pareça acessório e secundário, reduzindo proporcionalmente os investimentos na contratação de força de trabalho em relação ao capital fixo. Desse modo, a desconstrução do lugar do trabalhador na produção de riqueza está submetida ao apelo ideológico do capitalismo em defesa de sua manutenção. Mas, em contrapartida, a reprodução capitalista se faz com a desinserção dos trabalhadores, a readaptação e flexibilização, a perda de direitos e a desmobilização política, consequências que se aprofundam nos períodos de crise. 
Buscando viabilizar sua reprodução, o capitalismo se apropria das ferramentas necessárias para implementar a reorganização das relações sociais de produção de modo a desconstruir a noção de trabalho estável, admitindo a flexibilidade como elemento de modernidade e produtividade. Tal mudança ocorre não somente na dimensão técnica da produção com as novas tecnologias alterando o controle científico dos processos produtivos. Expressa, especialmente, mudança no campo ideológico, onde se faz crer que o modelo de trabalhador produtivo não combina com uma vida de trabalho em uma única ocupação. A flexibilidade no processo produtivo deve admitir que a empresa tenha liberdade na substituição de fatores produtivos em busca de maior produtividade, o que inclui a força de trabalho, permitindo a fácil adaptação às mudanças conjunturais da economia. Os contratos rígidos que impedem a mobilidade da força de trabalho terminam por prejudicar a expansão do capital.

Para viabilizar mais flexibilidade nas relações sociais de trabalho, tornou-se necessário desregulamentar e afrouxar as negociações entre patrões e empregados por meio da legislação trabalhista, o que se verifica em ações mais frequentes a partir dos anos de 1990 no Brasil, pondo-se em pauta a possibilidade de negociar férias, formar banco de horas, admitir o trabalho temporário, a ampliação da terceirização do trabalho, redução de salários, entre outras questões, visando mais flexibilidade da empresa nas formas de contratação da força de trabalho e proporcionar a manutenção dos lucros. Por outro lado, assume-se a defesa de menos Estado na economia, ao mesmo tempo em que se exige uma postura facilitadora na relação de forças entre capital e trabalho, argumento central utilizado pelo setor empresarial para enfrentar o problema do desemprego e da pobreza. Ou seja, supostamente, defende-se a salvação de alguns empregos às custas da perda de direitos trabalhistas.

Em uma nação que tem a pobreza como elemento de sua natureza, a necessidade de inserção social, a qualificação profissional e a empregabilidade, transformam-se em apelos insuperáveis sobre as possíveis perdas sociais. Contudo, as questões da desregulamentação do direito trabalhista e a flexibilização social do trabalho não são conjunturais, mas constituem instrumentos do processo de reestruturação do capital produtivo. Com a relativa recuperação da economia brasileira que atinge seu auge em 2010, a criação de mais empregos e a elevação do nível médio de renda, de certo modo, diminuíram a intensidade das reformas. 
Mas, com o fim do ciclo de crescimento, ressurgiu com mais força a demanda empresarial por flexibilização e desregulamentação do trabalho na segunda década deste século, juntamente com a regulamentação da ampliação da terceirização do trabalho sobre as atividades produtivas.

A crise na economia mundial e a dificuldade na retomada do crescimento serviram para aprofundar o cenário interno em meio às disputas políticas pelo poder. Apesar da instabilidade institucional, política e econômica, buscou-se criar um ambiente propício às principais reformas defendidas pela elite financeira e empresarial como necessárias para retomar o crescimento da economia brasileira com a ampliação da terceirização, a aprovação das reformas trabalhista e da previdência, todas compondo uma cesta básica de alargamento da flexibilização das relações de trabalho, desoneração dos custos das empresas com a força de trabalho e redução de direitos para o trabalhador.

Construiu-se uma "verdade" incontestável de que as reformas sobre o trabalho proporcionariam a criação de mais empregos e permitiriam maior autonomia para os trabalhadores, ao mesmo tempo em que facilitaria o processo de contratação pelos empresários. Os segmentos mais conservadores do capital assumiram com ânimo a defesa de menos Estado na economia e menos custos com a força de trabalho. Mesmo considerando que os elementos políticos apropriados pelo capital na relação com o Estado tenham encontrado ressonância nos grupos oportunistas desejosos em se manter ou entrar na dança do poder, não se observou uma postura mais qualitativa do segmento produtivo em propor políticas e ações estratégicas para reforçar e diversificar a capacidade produtiva, tendo em vista a competitividade acirrada no mercado mundial em função das mudanças nos padrões tecnológicos na transição para a indústria 4.0. Com exceção da demanda permanente por subsídios, redução de impostos e crédito, a indústria nacional não se preparou para as transformações estruturais do capital, o que a coloca em posição frágil, especialmente, quando os indicadores industriais expõem a diminuição relativa da participação do setor no PIB brasileiro, confirmando a tendência de desindustrialização no país.

As crises econômica e política apenas ampliaram este cenário de destruição do capital produtivo, na medida em que obstruíram e desarticularam as decisões de investimentos e a formulação de políticas de planejamento econômico. Por outro 
lado, redesenhou-se as características da expansão do capital com a consolidação da presença do capital financeiro sobre a economia produtiva. Neste contexto, a reforma trabalhista surge como fôlego necessário ao capital, nos seus diferentes setores, com o intuito de aumentar sua capacidade de expansão com a redução dos custos do trabalho. Na contramão do pacto entre Estado e capital, os trabalhadores assistem quase inertes às mudanças, tendo seus argumentos contrários às reformas amortecidos pelo aumento do desemprego. As primeiras reflexões sobre essas mudanças indicam que:

A reforma procura ampliar a liberdade das empresas manejar o trabalho de acordo com as suas necessidades, fundamentalmente buscando eliminar eventuais entraves ou obstáculos oriundos das instituições públicas. Assim, ela tem a finalidade de 'legalizar' práticas de flexibilização e de redução de custos e ampliar ainda mais o cardápio de opções de manejo da força de trabalho (KREIN; GIMENEZ; SANTOS, 2018, p. 120).

Criou-se a fábula de que os trabalhadores têm "direitos demais" e as perdas são necessárias para flexibilizar as contratações e permitir a retomada do crescimento do país. Ou seja, o trabalhador transformou-se em vilão e responsável pelos novos rumos da economia. Quanto ao aspecto político, as transformações estruturais na relação entre capital e trabalho promovem as condições institucionais para o desmonte da ação sindical, tendo em vista negociações desfavoráveis aos trabalhadores em função do aumento das desinserções, mas, sobretudo, com a condenação ao direito de greve, a obstrução das negociações coletivas, o aumento dos contratos intermitentes com efeito de desmobilização dos trabalhadores e as limitações impostas à contribuição sindical. Assim, as mudanças na legislação trabalhista, repercutindo diretamente sobre o encolhimento da ação dos sindicatos, expressam a legitimação da relação entre capital e Estado em detrimento dos direitos do trabalho para a manutenção das condições de expansão do modelo capitalista no Brasil, medidas não restritas aos setores produtivos tradicionais, mas que viabilizam a flexibilidade da absorção da força de trabalho, especialmente, nos setores de comércio e serviços.

A partir dessas mudanças estruturais e institucionais, vai sendo observada uma nova configuração da força de trabalho, sem lugar definido, mais flexível, com menos direitos, forçada a adaptar-se em função das tecnologias e das condições políticas. Este trabalhador sofre o desmonte da representação sindical como resultado do desgaste de uma pauta que parece caducar por estar baseada na 
manutenção de direitos e no trabalho estável. As alterações no padrão de acumulação cria a necessidade de um trabalhador autônomo e flexível, sujeito à negociação individual na venda da força de trabalho, mediante a fragilidade dos sindicatos e dos acordos coletivos. É esta força de trabalho mais barata e flexível que vem caracterizar as contratações nos setores de serviços e comércio, fenômeno que Antunes (2018) define como sendo o novo proletariado de serviços, como a expressão de diferentes formas de exploração e submissão do trabalho ao capital.

\begin{abstract}
Ao contrário da eliminação completa do trabalho pelo maquinário informacional-digital, estamos presenciando o advento e a expansão monumental do novo proletariado da era digital, cujos trabalhos, mais ou menos intermitentes, mais ou menos constantes, ganharam novo impulso com as TICs [Tecnologias da Informação e Comunicação], que conectam, pelos celulares, as mais distintas modalidades de trabalho. Portanto, em vez do fim do trabalho na era digital, estamos vivenciando o crescimento exponencial do novo proletariado de serviços, uma variante global do que se pode denominar escravidão digital em pleno século XXI (ANTUNES, 2018, p. 30).
\end{abstract}

Assim se observa a renovação da disponibilidade do trabalho no capitalismo, modelo que se encarrega de desqualificar, periodicamente, os papéis políticos e econômicos para que seja renovado o pacto social de submissão e controle da força de trabalho disponível.

O século XXI expõe os trabalhadores às novas tecnologias da informação que impõem mais agilidade na comunicação e nos processos de trabalho. Por outro lado, nem todos serão mantidos como úteis ou conseguirão se adaptar a essas tecnologias absorvidas pelos setores produtivos, inclusive porque verifica-se a tendência de diminuição relativa da força de trabalho empregada e pela queda na participação do setor industrial na criação de empregos formais. Desse modo, assiste-se ao avanço significativo do setor de serviços que tende a incorporar as inovações das tecnologias da informação para diversificar as atividades, aproveitando-se dessa força de trabalho flexível e autônoma, submetida às novas modalidades de contratos de trabalho e à condição de não ter direitos. Como consequência naturalizada das transformações do trabalho, todas as formas de permanência da sobrevivência são possíveis, ampliando-se a precarização e a informalidade do trabalho. O sujeito assume o caráter de trabalhador flexível na luta 
para existir em uma sociedade que tenta negar sua existência e a centralidade do seu trabalho.

Há que se considerar o modelo do trabalhador autônomo e empreendedor se manifestando também na informalidade e se alimentando de atividades precárias, com jornadas de trabalho intensivas e baixos rendimentos, mas que ideologicamente estão sustentadas na ilusão da liberdade de iniciativa e criatividade. Neste contexto, o trabalhador transforma-se em gestor da própria exclusão e, de fato, precisa ser criativo para sobreviver, pois cada um terá o melhor possível diante das condições individuais disponíveis. Como consequência, perde-se aparentemente o sentido do trabalho coletivo e sua capacidade de representação, pois a luta é para sobreviver e está estabelecida no campo individual como pleno exercício da submissão e da exploração.

Esta configuração do trabalho apresenta-se dialeticamente como a gestação de novas formas de ocupações entre o capital e o trabalho, tendo em vista que ao mesmo tempo que esta relação destrói os lugares do trabalho formal nas atividades tradicionais, cria e recria ocupações que vão do formal ao informal na mística do empreendedorismo, explicitando a centralidade do trabalho humano como essência do sistema produtivo, mesmo que sobreviva à margem deste.

\section{COMPORTAMENTO RECENTE DO EMPREGO E OS POSSÍVEIS IMPACTOS DA FLEXIBILIZAÇÃO DO TRABALHO SOBRE AS OCUPAÇÕES NO BRASIL}

O mercado de trabalho no Brasil é marcado pela heterogeneidade, tendo a precariedade e informalidade como fenômenos típicos de uma economia que se desenvolve historicamente pela reprodução das desigualdades. As diferenças regionais, no rural e no urbano, por gênero, raça, ocupações e rendimentos no âmbito do trabalho, por si só, apresentam desafios estruturais a serem enfrentados pelas políticas de planejamento econômico e emprego.

Neste sentido, é importante analisar a estrutura e o comportamento recente do mercado de trabalho no Brasil e os possíveis impactos da flexibilização sobre as condições dos trabalhadores. Quanto a distribuição das pessoas por categoria do emprego no Brasil (Tabela 1), observou-se queda de mais de 1 ponto percentual nos empregados no setor privado entre 2015 e 2018, de acordo com os dados da Pesquisa Nacional por Amostra de Domicílios Contínua (PNADC), do Instituto 
Brasileiro de Geografia e Estatística (IBGE). Os trabalhadores empregados com carteira assinada também sofreram redução de cerca de 3 pontos percentuais, com 2 milhões de pessoas a menos. Em contrapartida, foi registrado aumento do número de trabalhadores sem carteira de trabalho assinada.

Tabela 1 - Pessoas* por posição na ocupação e categoria do emprego no trabalho principal de 2015 a $2018(\%)$

\begin{tabular}{l|r|r|r|r}
\multicolumn{1}{c|}{ Categoria do emprego } & $\mathbf{2 0 1 5}$ & $\mathbf{2 0 1 6}$ & \multicolumn{1}{c|}{$\mathbf{2 0 1 7}$} & \multicolumn{1}{c}{$\mathbf{2 0 1 8}$} \\
\hline $\begin{array}{l}\text { Empregado no setor privado, exclusive trabalhador } \\
\text { doméstico }\end{array}$ & 49,70 & 49,15 & 48,58 & 48,03 \\
\hline $\begin{array}{l}\text { Empregado no setor privado, exclusive trabalhador } \\
\text { doméstico - com carteira de trabalho assinada }\end{array}$ & 38,75 & 37,95 & 36,80 & 35,85 \\
\hline $\begin{array}{l}\text { Empregado no setor privado, exclusive trabalhador } \\
\text { doméstico - sem carteira de trabalho assinada }\end{array}$ & 10,93 & 11,23 & 11,83 & 12,15 \\
\hline Trabalhador doméstico & 6,58 & 6,85 & 6,83 & 6,78 \\
\hline Trabalhador doméstico - com carteira de trabalho assinada & 2,15 & 2,30 & 2,05 & 2,00 \\
\hline Trabalhador doméstico - sem carteira de trabalho assinada & 4,45 & 4,58 & 4,78 & 4,80 \\
\hline Empregado no setor público & 12,38 & 12,40 & 12,45 & 12,58 \\
\hline Empregador & 4,35 & 4,33 & 4,65 & 4,83 \\
\hline Conta própria & 24,13 & 24,90 & 25,03 & 25,40 \\
\hline Trabalhador familiar auxiliar & 2,80 & 2,35 & 2,45 & 2,38 \\
\hline Fonte: PNADC. Elabo
\end{tabular}

Fonte: PNADC. Elaboração própria, 2019. *14 anos ou mais de idade, ocupadas na semana de referência.

No segmento específico do trabalho doméstico, verificou-se aumento no número de pessoas ocupadas, mas com queda nos empregados com carteira assinada e aumento das pessoas sem carteira no período analisado. Destacando as pessoas sem carteira de trabalho e os que sobrevivem por conta própria, em 2018, alcançava-se $37,55 \%$, o que representa cerca de 35 milhões de pessoas sobrevivendo nessas condições de trabalho, superior a 35,08\% obtido em 2015. Este aumento significativo de desinserções no trabalho formal e elevação nas atividades informais e por conta própria pode ser o reflexo da crise política e econômica observadas neste período, assim como também apresenta uma tendência do tipo de ocupação que vem sendo criada com o crescimento do setor de serviços.

Os indicadores da Tabela 2 destacaram o trabalho principal das pessoas ocupadas por grupos de atividades para o Brasil. Entre 2015 e 2018, os setores que 
apresentaram retração nas ocupações foram: agricultura, indústria e construção civil, com queda em torno de 1 ponto percentual cada um. As atividades ligadas ao comércio se mantiveram relativamente estáveis e os serviços registraram discreto crescimento, tendo se destacado o subsetor de alojamento e alimentação com alta de 1 ponto percentual. Em geral, este último segmento é capaz de absorver mais facilmente as pessoas que perderam seus empregos e buscam outras formas de inserção no mercado informal ou como pequenos empreendedores, adaptando-se e desenvolvendo a produção de alimentos, pequenos reparos domésticos, entre outros.

Tabela 2 - Distribuição das pessoas* por tipo de atividade no trabalho principal de 2015 a 2018 (\%)

\begin{tabular}{l|r|r|r|r}
\hline \multicolumn{1}{c|}{ Grupamento de atividades no trabalho principal } & $\mathbf{2 0 1 5}$ & $\mathbf{2 0 1 6}$ & $\mathbf{2 0 1 7}$ & $\mathbf{2 0 1 8}$ \\
\hline Agricultura, pecuária, produção florestal, pesca e aquicultura & 10,30 & 10,18 & 9,50 & 9,33 \\
\hline Indústria geral & 14,00 & 12,80 & 12,93 & 12,83 \\
\hline Indústria de transformação & 12,55 & 11,45 & 11,53 & 11,48 \\
\hline Construção & 8,13 & 8,05 & 7,55 & 7,25 \\
\hline Comércio, reparação de veículos automotores e motocicletas & 19,10 & 19,25 & 19,33 & 19,10 \\
\hline Transporte, armazenagem e correio & 4,70 & 5,00 & 5,05 & 5,08 \\
\hline Alojamento e alimentação & 4,78 & 5,13 & 5,65 & 5,78 \\
\hline $\begin{array}{l}\text { Informação, comunicação e atividades financeiras, imobiliárias, } \\
\text { profissionais e administrativas }\end{array}$ & 11,20 & 10,73 & 11,03 & 11,03 \\
\hline $\begin{array}{l}\text { Administração pública, defesa, seguridade social, educação, saúde } \\
\text { humana e serviços sociais }\end{array}$ & 16,68 & 17,25 & 17,15 & 17,50 \\
\hline Outro serviço & 4,53 & 4,70 & 4,98 & 5,25 \\
\hline Serviço doméstico & 6,60 & 6,90 & 6,88 & 6,83 \\
\hline
\end{tabular}

Fonte: PNADC. Elaboração própria, 2019.

*14 anos ou mais de idade, ocupadas na semana de referência.

Confirma-se o aumento das pessoas ocupadas por conta própria e sem carteira de trabalho assinada, definindo um perfil de trabalhadores que ainda podem estar envolvidos em atividades precárias, com elevadas jornadas de trabalho e sem proteção social. Quanto à contribuição para a previdência social, entre 2015 e 2018, foi observada queda de $2,8 \%$ no número de pessoas contribuintes, enquanto houve aumento de $1,8 \%$ para as pessoas que não contribuem com a previdência. No ano de 2018 , cerca de $63 \%$ dos trabalhadores realizavam contribuição previdenciária. Já os não contribuintes expressavam $36 \%$. Assim, alerta-se para o fato de muitas pessoas estarem desenvolvendo atividades precárias e sem a garantia dos direitos sociais do trabalho, reforçando a permanência na informalidade. 
No tocante aos rendimentos do trabalho principal, entre 2015 e 2018, os trabalhadores empregados no setor privado apresentaram os maiores valores, com crescimento de 5,56\% (Tabela 3 ). Por outro lado, além de serem remunerados abaixo da renda média, os trabalhadores por conta própria sofreram queda de 4,2\% em seus rendimentos. A renda média dos empregadores também apresentou declínio, o que pode indicar maiores dificuldades de permanência das empresas no mercado frente à crise. De todo modo, aqueles trabalhadores que conseguem se manter empregados com carteira assinada ainda têm a oportunidade de assegurar rendimentos em melhores condições.

Tabela 3 - Rendimento médio real das pessoas no trabalho principal de 2015 a $2018(R \$)$

\begin{tabular}{l|r|r|r|r}
\hline \multirow{2}{*}{ Ano } & \multicolumn{5}{|c}{ Posição na ocupação no trabalho principal } \\
\cline { 2 - 5 } & \multicolumn{1}{|l|}{ Total } & Empregado & Empregador & Conta própria \\
\hline 2015 & $\mathrm{R} \$ 2.194,75$ & $\mathrm{R} \$ 2.154,75$ & $\mathrm{R} \$ 5.776,50$ & $\mathrm{R} \$ 1.655,50$ \\
\hline 2016 & $\mathrm{R} \$ 2.202,25$ & $\mathrm{R} \$ 2.216,50$ & $\mathrm{R} \$ 5.514,75$ & $\mathrm{R} \$ 1.586,00$ \\
\hline 2017 & $\mathrm{R} \$ 2.262,67$ & $\mathrm{R} \$ 2.281,00$ & $\mathrm{R} \$ 5.730,33$ & $\mathrm{R} \$ 1.563,00$ \\
\hline 2018 & $\mathrm{R} \$ 2.252,00$ & $\mathrm{R} \$ 2.274,00$ & $\mathrm{R} \$ 5.463,75$ & $\mathrm{R} \$ 1.585,50$ \\
\hline
\end{tabular}

Fonte: PNADC. Elaboração própria, 2019.

*14 anos ou mais de idade, ocupadas na semana de referência.

Observando os grupos de atividades para o Brasil, os maiores rendimentos do trabalho principal encontram-se no setor de administração pública, defesa, seguridade social, educação, saúde e serviços sociais, o que é uma característica comum também para estados e municípios, já que é neste segmento onde está concentrado o maior número de pessoas empregadas no trabalho estável e com carteira de trabalho assinada. Em seguida aparece o setor de informação, comunicação e atividades financeiras, imobiliárias e administrativas, demonstrando o crescimento, em especial, das atividades financeiras e imobiliárias na fase recente. A indústria geral, apesar de apresentar remunerações acima da média nacional, manteve-se relativamente estável no período, mas com queda na indústria de transformação. No caso do setor da construção civil, foi observada redução de 2,7\% nos rendimentos do trabalho, situação que já pode ser reflexo da diminuição do ritmo de atividade no setor. Um detalhe importante a ser observado é que, enquanto o setor de alojamento e alimentação apresentou aumento no pessoal empregado entre 2015 e 2018, o rendimento médio ficou em $R \$ 1.471,50$, abaixo da média nacional, 
além de registrar queda de $6,4 \%$ no período (Tabela 4). Tal fato pode estar associado a manutenção de ocupações frágeis que geram baixos rendimentos.

Tabela 4 - Rendimento médio real das pessoas por grupos de atividades do trabalho principal de 2015 a $2018(\mathrm{R} \$)$

\begin{tabular}{l|r|r|r|r}
\multicolumn{1}{c|}{ Atividades } & \multicolumn{1}{c|}{$\mathbf{2 0 1 5}$} & \multicolumn{1}{c|}{$\mathbf{2 0 1 6}$} & \multicolumn{1}{c|}{$\mathbf{2 0 1 7}$} & \multicolumn{1}{c}{$\mathbf{2 0 1 8}$} \\
\hline Total & \multicolumn{1}{c|}{$2.160,50$} & \multicolumn{1}{c}{$2.121,50$} & $2.164,00$ & \multicolumn{1}{c}{$2.173,00$} \\
\hline $\begin{array}{l}\text { Agricultura, pecuária, produção florestal, } \\
\text { pesca e aquicultura }\end{array}$ & $1.232,25$ & $1.192,25$ & $1.285,25$ & $1.273,25$ \\
\hline Indústria geral & $2.256,25$ & $2.177,75$ & $2.209,25$ & $2.260,50$ \\
\hline Indústria de transformação & $2.177,25$ & $2.113,50$ & $2.130,00$ & $2.158,00$ \\
\hline Construção & $1.789,00$ & $1.793,00$ & $1.755,00$ & $1.741,25$ \\
\hline $\begin{array}{l}\text { Comércio, reparação de veículos } \\
\text { automotores e motocicletas }\end{array}$ & $1.840,75$ & $1.799,00$ & $1.808,75$ & $1.787,75$ \\
\hline Transporte, armazenagem e correio & $2.273,00$ & $2.297,50$ & $2.499,00$ & $2.180,50$ \\
\hline Alojamento e alimentação & $1.572,25$ & $1.503,00$ & $1.453,25$ & $1.471,50$ \\
\hline $\begin{array}{l}\text { Informação, comunicação e atividades } \\
\text { financeiras, imobiliárias e administrativas }\end{array}$ & $3.161,75$ & $3.177,50$ & $3.249,50$ & $3.254,25$ \\
\hline $\begin{array}{l}\text { Admin. pública, defesa, seguridade, } \\
\text { educação, saúde e serviços sociais }\end{array}$ & $3.164,75$ & $3.151,50$ & $3.205,00$ & $3.305,75$ \\
\hline Outros serviços & $1.734,25$ & $1.635,25$ & $1.656,50$ & $1.661,25$ \\
\hline Serviço doméstico & 878,25 & 880,25 & 886,75 & 888,00 \\
\hline Atividades mal definidas & $1.788,50$ & $1.966,25$ & $1.342,00$ & $1.997,50$ \\
\hline Fonn & & &
\end{tabular}

Fonte: PNADC Trimestral. Elaboração própria, 2019.

*14 anos ou mais de idade, ocupadas na semana de referência.

Ainda no âmbito dos serviços, o trabalho doméstico foi o que apresentou os menores rendimentos, expondo a vulnerabilidade das pessoas empregadas nessa atividade, sendo a maioria de mulheres e negras, com forte participação do trabalho sem carteira assinada.

No que se refere ao emprego formal no Brasil, de acordo com os dados do Cadastro Geral de Empregados e Desempregados (CAGED), da Secretaria de Trabalho, de janeiro a dezembro de 2018, o setor de serviços foi o que gerou o maior número de ocupações, com $42 \%$ das admissões. Em seguida apareceu o comércio, com $25 \%$, a indústria de transformação, com $16 \%$, e construção civil, com $9 \%$. Os dados demostram a dimensão e importância do setor de serviços para 0 emprego que, juntamente com o comércio, exibiram quase $70 \%$ dos empregos formais criados no país.

Colocando em evidência o setor de serviços, o saldo de admissões menos desligamentos para o emprego formal, apresentou retração em três anos 
consecutivos de 2015 a 2017, refletindo a reação do setor à crise econômica. Em 2018, os empregos no setor voltaram a apresentar saldo positivo, mas com desaceleração em 2019, considerando os meses de janeiro (Tabela 5). O subsetor de transporte e comunicação registrou saldo negativo em todo período. No caso dos serviços ligados a alojamento e alimentação, também foram destaque as oscilações negativas no período e a dificuldade em manter o saldo positivo em janeiro de 2019. Por outro lado, os dados da PNADC mostraram crescimento do número de pessoas que declararam o trabalho principal nestas atividades, indicando a possibilidade de que as ocupações também estejam sendo criadas na informalidade.

O grupo que abrange as atividades imobiliárias foi o de maior expressão para novas contratações em janeiro de 2019 , com mais de $50 \%$ dos empregos formais, o que mostra a manutenção da atividade no segmento, apesar do ciclo de queda no setor da construção civil.

Tabela 5 - Evolução mensal do saldo de emprego por ramos do setor de serviços nos meses de janeiro de 2014 a 2019 (Saldo e \%)

\begin{tabular}{l|r|r|r|r|r|r}
\hline \multicolumn{1}{c|}{ Mês/ Ano } & Jan./14 & Jan./15 & \multicolumn{1}{c|}{ Jan./16 } & Jan./17 & Jan./18 & Jan./19 \\
\hline SERVIçOS & 24.681 & -7.141 & -17.159 & -9.525 & 46.544 & 43.449 \\
\hline $\begin{array}{l}\text { Instituiçães de Créd. Seg. e } \\
\text { de Capital }\end{array}$ & -567 & 1.135 & 820 & -711 & 1.930 & 971 \\
\hline $\begin{array}{l}\text { Comércio e administração } \\
\text { de imóveis, Serviços }\end{array}$ & 15.311 & 2.959 & -5.663 & 3.266 & 22.926 & 23.318 \\
$\begin{array}{l}\text { Técnicos-Profissionais } \\
\text { Transporte e Comunicação }\end{array}$ & -3.663 & -9.995 & -13.993 & -10.235 & -4.921 & -2.513 \\
\hline $\begin{array}{l}\text { Serviços de Alojamento e } \\
\text { Alimentação, Rep. } \\
\text { Manutenção }\end{array}$ & 1.926 & -7.270 & -2.267 & -7.129 & 9.827 & 1.358 \\
\hline $\begin{array}{l}\text { Serv. Médicos, Odont. e } \\
\text { Veterinários }\end{array}$ & 7.596 & 3.992 & 2.847 & 2.076 & 8.701 & 15.163 \\
\hline Ensino & 4.078 & 2.038 & 1.097 & 3.208 & 8.081 & 5.152 \\
\hline
\end{tabular}

Fonte: CAGED/MTE, 2019.

Sobre os vínculos empregatícios dos trabalhadores, observou-se queda expressiva dos contratos regidos pela Consolidação das Leis do Trabalho (CLT), entre 2015 e 2018, confirmando a fase mais intensa de desinserções em função da crise econômica. Os setores mais afetados foram: indústria de transformação, serviços e construção civil. Por outro lado, o setor do comércio foi o que registrou o pior desempenho quanto à contratação de trabalhadores celetistas, com saldos negativos em todo período. Contudo, apesar da situação de crise ter afetado 
significativamente 0 setor, muitos pequenos estabelecimentos surgiram como resultado das estratégias de pessoas que buscam o comércio como atividade principal do trabalho e se transformaram em empregadores, aumentando o potencial de empregabilidade. De acordo com a FECOMÉRCIO de São Paulo, os empreendimentos classificados como Microempreendedores Individuais (MEI), que podem empregar até um funcionário com carteira assinada, e as empresas com até quatro funcionários, foram responsáveis pelo maior número de contratações em 2018. No final do período, novamente observa-se a diminuição dos contratos celetistas, confirmando a tendência de desativação de ocupações formais em meio ao aumento do trabalho sem carteira de trabalho assinada e por conta própria.

A partir de 2009, quando entrou em vigor a legislação que definiu os MEls no Brasil, observou-se o progressivo crescimento de pessoas buscando se enquadrar como empreendedores, o que na verdade veio permitir a formalização de milhares de trabalhadores que realizam atividades produtivas e trabalho informal. Até janeiro de 2019, de acordo com o Portal do Empreendedor, havia mais de 7,5 milhões de registros formais de MEls, considerando os que estão inscritos no Sistema de Recolhimento em Valores Fixos Mensais dos Tributos do Simples Nacional - SIMEI. Especialmente no período de crise mais acentuada em que se observou aumento do desemprego, do trabalho informal e por conta própria, foi registrado crescimento bastante expressivo de 66\% de novos MEls formais entre 2015 e 2018, demonstrando explicitamente a formalização da informalidade em um cenário de desinserções. Entre janeiro 2018 e 2019, houve diminuição no ritmo do crescimento dos registros dos MEls, o que pode traduzir certa acomodação, dada a rápida ascensão nos anos anteriores, além do desestímulo à abertura de novos negócios devido ao fraco desempenho dos setores de comércio e serviços que abrigam a maior parte dos pequenos empreendimentos. Os indicadores evidenciam a mudança estrutural na criação de ocupações do trabalho principal, confirmando o crescimento do setor de comércio e serviços como tendência.

Considerando o total de MEls abertos por atuação no Brasil, conforme a Tabela 6, os estabelecimentos fixos representam cerca de 45\% dos negócios. Em segundo lugar aparecem as atividades de porta a porta e ambulantes, com 25\%, seguido pelas pequenas empresas que atuam com a internet, com 11\%, e as que se distribuem em local fixo (fora da loja), com 10\%. Das pessoas que trabalham por 
conta própria, muitas estão integradas como MEls, mas parte significativa de pessoas desempenham suas atividades na informalidade.

Tabela 6: Brasil - total de empresas optantes no SIMEI, por forma de atuação

\begin{tabular}{l|r|r}
\hline \multicolumn{1}{c|}{ Forma Atuação } & \% Brasil & \multicolumn{1}{c}{ MEI } \\
\hline \multicolumn{1}{c|}{ Total } & $100 \%$ & 11.060 .966 \\
\hline Estabelecimento fixo & $45,41 \%$ & 5.022 .797 \\
\hline Porta a Porta, postos móveis ou por ambulantes & $24,95 \%$ & 2.760 .029 \\
\hline Internet & $11,59 \%$ & 1.282 .169 \\
\hline Em local fixo, fora da loja & $10,27 \%$ & 1.136 .034 \\
\hline Televendas & $3,95 \%$ & 436.716 \\
\hline Correios & $2,78 \%$ & 307.906 \\
\hline Máquinas automáticas & $1,04 \%$ & 115.315 \\
\hline
\end{tabular}

Fonte: Portal do Empreendedor, 2019.

De acordo com a PNAD, em 2017, 29\% das pessoas no trabalho por conta própria eram homens, e 20\% mulheres. Quanto à previdência social, apenas 7,7\% dos trabalhadores por conta própria realizaram contribuição no Brasil. No caso dos trabalhadores sem carteira assinada, os que contribuíram para a previdência social foram apenas $4,4 \%$ no mesmo ano.

Considerando, ainda, os indicadores da PNAD, quanto à natureza das atividades, $43 \%$ das ocupações por conta própria foram desempenhadas no setor da agropecuária, $19 \%$ na indústria, $51 \%$ na construção civil, $27 \%$ no comércio e $32 \%$ nos demais serviços. Esses dados podem indicar a proliferação dos microempresários em todos os setores, mas ao mesmo tempo observa-se a expansão da gestão individual da força de trabalho na oferta de pequenos serviços no trabalho como o de eletricistas, encanadores, na produção e comercialização dos produtos de pequenos agricultores familiares, em serviços de manicures, alimentação, vendedores de porta em porta e até os serviços ofertados a partir dos canais da internet.

A PNAD também apresenta a distribuição dos trabalhos formais e informais por setores produtivos. Destacando os dados para o ano de 2017, no setor da agropecuária, $31,4 \%$ são atividades formais, enquanto 68,5\% informais; no segmento industrial, a distribuição fica em $71,7 \%$ e $28,3 \%$; no comércio com $62,2 \%$ e $37,8 \%$, respectivamente. Nos demais serviços, o trabalho formal ocupa $62,5 \%$ e o 
informal $37,5 \%$ das atividades. Ponderando todas as atividades, o trabalho informal tem peso de mais de $40 \%$ nas ocupações produtivas, com presença marcante nos setores da agropecuária, comércio e serviços.

É possível que o processo de desregulamentação e flexibilização da força de trabalho em curso, tendo como consequência o desmonte dos direitos sociais pelo trabalho, o aumento das desinserções e o surgimento de novas ocupações informais e precárias como meio de sobrevivência, venha provocar o alargamento da desigualdade social no Brasil, reforçada pela ausência de políticas públicas efetivas e sustentáveis de distribuição de renda e inserção social.

\section{CONSIDERAÇÕES FINAIS}

Estamos vivendo tempos de desmonte de direitos do trabalho. Contudo, apesar de parecer naturalizado, a força com que vem ocorrendo as transformações, mais do que afetar a relação de submissão formal do trabalho ao capital, significa a destruição do espaço coletivo das lutas dos trabalhadores por melhores condições de trabalho, salários justos, descanso e, sobretudo, dignidade. Ao trabalhador, resta resignar-se em perder direitos para manter o emprego.

Neste movimento, as inovações tecnológicas contribuem para acelerar as desinserções e desqualificar o trabalhador que precisa se mostrar proativo, competente e flexível para se manter útil ao capital. Recicla-se também as ideias e as condutas do trabalhador, na medida em que este sujeito descartado e tendo perdido a identidade do trabalho coletivo e estável, passa a incorporar os conceitos individualizantes de gestores autônomos da força de trabalho, ou empreendedores individuais, livres para encontrar outros espaços de submissão. Longe de parecer livre, o trabalho autônomo ou empreendedor não assegura liberdade, pois cria uma legião de pessoas dispostas a cumprir jornadas de trabalho exaustivas, não ter férias e experimentar as mais variadas atividades, seja na formalidade ou não, para sobreviver.

A flexibilização das relações de trabalho, culminando nas reformas institucionais que permitem a perda de direitos sociais do trabalho, sustentadas na farsa de que mais empregos serão gerados, não pode assegurar ao trabalhador o direito ao trabalho, pois a reforma estrutural do capital na fase contemporânea veio reforçar a situação de instabilidade e a destruição de ocupações produtivas formais. 
Tende a se ampliar as atividades e postos informais de trabalho, ao mesmo tempo em que parte dos trabalhadores estarão dispostos ao trabalho por conta própria, configurando-se em gestores individuais da exclusão, disfarçados de empreendedores capitalistas.

Os indicadores em destaque sobre mercado de trabalho evidenciam nos anos recentes o aumento das ocupações por conta própria, a informalidade do trabalho e o crescimento dos microempreendedores individuais, expressão das condições estruturais de um ambiente econômico incapaz de criar condições dignas de trabalho formal. Por outro lado, essa tendência pode reforçar significativamente as atividades que se desenvolvem com as características de trabalho e produtos precários, gerando baixas remunerações, fatores que contribuem para a preservação e reprodução da pobreza e das desigualdades. Ainda que essas condições sejam evidentes, a relação entre Estado e capital deve se estender para consolidar o cerceamento da capacidade de mobilização coletiva dos trabalhadores, já que está assinalada para garantir a legitimidade das reformas que retiram direitos do trabalho e promove a redução dos custos trabalhistas para os empregadores.

$O$ que se presencia no momento é a responsabilização individual do trabalhador por sua instrução básica e formação profissional, por sua inserção e por sua exclusão, por suas capacidades e incompetências, e por se resignar em ter direitos a menos. Numa sociedade como a brasileira com déficits históricos em educação, saúde, moradia, cultura, e tantos outros, e em que o trabalho não pode garantir direitos de cidadania, só é possível apostar no alargamento das desigualdades sociais e temer por suas consequências.

\section{REFERÊNCIAS}

ANTUNES, Ricardo. O privilégio da servidão: o novo proletariado de serviços na era digital. São Paulo, Boitempo, 2018.

Os sentidos do trabalho: ensaio sobre a afirmação e a negação do trabalho. São Paulo: Boitempo Editorial, 1999.

ARENDT, H. A condição humana. 10ª edição, Rio de Janeiro: Forense Universitária, 2009. 
AZEREDO, B.. Políticas públicas de geração de emprego no Brasil: limites e possibilidades. In: OLIVEIRA, M. A. de (Org.). Reforma do Estado e políticas de emprego no Brasil. Campinas: Unicamp-IE, 1998.

CAGED/MTE - Cadastro Geral de Empregados e Desempregados/Ministério do Trabalho e Emprego. Disponível em: <http://trabalho.gov.br/dados-abertos> Obtido em: 20 de fevereiro de 2019.

CASTEL, R.. As metamorfoses da questão social: uma crônica do salário. Petrópolis: Editora Vozes, 1998.

CASTELLS, M.. A sociedade em Rede. 9aㅗ ed. São Paulo: Paz e Terra, 2006.

DEDECCA, C. S.. Emprego e qualificação no Brasil dos anos 90. In: OLIVEIRA, M. A. de (Org.). Reforma do Estado e políticas de emprego no Brasil. Campinas: Unicamp-IE, 1998.

MARX, K.. O capital: crítica da economia política. 12ª edição. Rio de Janeiro: Bertrand Brasil, V. I., 1989.

MÉSZAROS, I. O desafio e o fardo do tempo histórico. São Paulo: Boitempo, 2007.

KREIN, José Dari; GIMENEZ, Denis Maracci e SANTOS, Anselmo Luis dos. (Orgs.). Dimensões críticas da reforma trabalhista no Brasil. Campinas, São Paulo: Curt Nimuendajú, 2018.

LEITE, M. de P.. O futuro do trabalho: novas tecnologias e subjetividade operária. São Paulo: Scritta/Fapesp, 1994.

PNADC/IBGE - Pesquisa Nacional por Amostra de Domicílio Contínua Trimestral/Instituto Brasileiro de Geografia e Estatística. Disponível em: $<$ https://sidra.ibge.gov.br/pesquisa/pnadct/ tabelas> Obtido em: 20 de fevereiro de 2019.

PNAD/IBGE - Pesquisa Nacional por Amostra de Domicílio/Instituto Brasileiro de Geografia e Estatística. Disponível em:

$<$ https://www.ibge.gov.br/estatisticas-novoportal/ multidominio/genero/9221-sintesede-indicadores-sociais.html?=\&t=resultados $>$ Obtido em: 20 de fevereiro de 2019.

PORTAL DO EMPREENDEDOR. Disponível em:

$<$ http://www.portaldoempreendedor.gov.br /estatisticas> Obtido em: 06 de março de 2019.

RAIS/MTE - Relação Anual de Informações Sociais/Ministério do Trabalho e Emprego. Disponível em: < http://trabalho.gov.br/dados-abertos> Obtido em: 20 de fevereiro de 2019. 